\title{
Loneliness Corresponds with Politically Conservative Thought
}

\author{
Kory Floyd* \\ Department of Communication, University of Arizona, Tucson AZ \\ *Corresponding author: koryfloyd@email.arizona.edu
}

\begin{abstract}
A formidable empirical literature describes loneliness as a perceived deficiency in social connection and inclusion associated with a range of mental and physical health problems and multiple maladaptive coping strategies. Many of these negative consequences can be accounted for by Cacioppo, Cacioppo, and Boomsma's evolutionary theory of loneliness, which reasons that a lack of adequate interpersonal connection is aversive because, evolutionarily, such a detriment posed threats to the ability of individuals to survive and reproduce. The theory proposes that loneliness therefore produces feelings of heightened anxiety and perceptions of vulnerability to threat that motivate individuals to attend to their relational needs. In modernity, heightened anxiety and perceptions of threat also correspond to politically conservative ideologies, such as a fear of foreigners (xenophobia), a preference for authoritarianism, and a lack of tolerance for distress. Working from the premise of Cacioppo's theory, the present study therefore reasoned that loneliness is associated with endorsement of such politically conservative values. A nationwide survey of 848 American adults confirmed that loneliness is positively correlated with xenophobia and endorsement of right-wing authoritarianism and negatively associated with distress tolerance.
\end{abstract}

Keywords: loneliness, social isolation, political conservatism, Cacioppo, Cacioppo's evolutionary theory of loneliness

Cite This Article: Kory Floyd, "Loneliness Corresponds with Politically Conservative Thought." Research in Psychology and Behavioral Sciences, vol. 5, no. 1 (2017): 13-21. doi: 10.12691/rpbs-5-1-3.

\section{Introduction}

Humans are a profoundly social species. Maslow's theory of human motivation, Schutz's fundamental interpersonal relations orientation theory, and Baumeister and Leary's need-to-belong theory all identify quality social relationships as paramount for human wellness $[1,2,3]$. Contrariwise, a robust empirical literature details the variety of mental and physical health detriments associated with a lack of social connection $[4,5,6]$. Importantly, it is the perception of social isolation-rather than any objective measure of social connectedness - that is primarily problematic [7]. When individuals perceive a discrepancy between their desired and experienced levels of social connection - a condition known as lonelinessthey are susceptible to detriments in their health and well-being irrespective of their marital status, parenthood status, frequency of contact with friends, participation in social or religious groups, or other objective markers of social engagement [8].

Cacioppo, Cacioppo, and Boomsma have advanced an evolutionary theory of loneliness to account for the formidable causal and correlational associations between loneliness and wellness [9]. This paper argues that their evolutionary account implies that loneliness corresponds not only to mental and physical health detriments but also to political and social values. Specifically, loneliness prompts individuals to see the world as threatening and anxiety-producing, which typically is associated with political ideologies that are more conservative than liberal. This review begins by defining loneliness and articulating Cacioppo's theory. Research linking anxiety and perceived threat to stereotypically conservative values is then described, and hypotheses connecting loneliness to political conservatism are advanced.

\section{Loneliness}

Loneliness fundamentally comprises a discrepancy between desired and experienced social connection. Cacioppo and colleagues defined loneliness as "a complex set of feelings that occurs when intimate and social needs are not adequately met" [10]. Importantly, solitude is neither necessary nor sufficient for loneliness to emergepeople can be alone without feeling lonely and can experience loneliness even when surrounded by others.

Many people experience states of loneliness intermittently. This is a normal response to changes in their social circumstances and one that is probably even adaptive, insofar as it stimulates efforts to make or renew social connections [4]. Intermittent loneliness stands in contrast to chronically elevated loneliness, a condition that afflicts many and is concentrated in particular demographic groups, such as adolescents and older adults. Victor and Yang found a curvilinear relationship between loneliness and age in which the highest rates of loneliness characterized adults under 25 years of age and over 65 years of age [11]. 
A U.S. study by the American Association of Retired Persons (AARP) of adults 45 years of age and older found that $36 \%$ reported chronic loneliness (operationally defined as a score of $\geq 44$ on the UCLA Loneliness Scale, described below) [12]. Loneliness was most prevalent (43\%) for adults aged 45-49 and became decreasingly prevalent with increasing age. In comparison, Theeke reported a loneliness prevalence rate of $19.3 \%$ for adults 65 years of age and older, using data from a nationally representative study of U.S. senior citizens [13].

Reports confirm that loneliness is not solely an American cultural affliction. For instance, a study of 1,299 adults aged 65 and over in the United Kingdom documented a loneliness rate of $35 \%$, with $9 \%$ describing their loneliness as painful [14]. Similarly, in a study of U.S. Chinese senior citizens, Simon, Chang, Zhang, Ruan, and Dong found that $20.5 \%$ of participants reported a lack of companionship, 18.5\% reported feeling "left out of life," and $6.2 \%$ reported feeling isolated [15]. The overall prevalence of any loneliness symptom was $26.2 \%$. Unlike the AARP study, Simon and colleagues found that loneliness among Chinese senior citizens increased with age, although it was more prevalent among women and among those living alone. Other reports have also shown loneliness to vary by sex. In a survey of 6,500 U.S. adults, Steptoe, Shankar, Demakakos, and Wardle found that $36.7 \%$ of men and $63.3 \%$ of women reported high levels of loneliness (a significant sex difference) [8].

Loneliness is associated with a wide range of physical health disorders and disturbances. These include pain and fatigue [16], sleep disturbances [17], hypertension [18], lack of physical activity [19], and inflammatory responses to stress [20]. Loneliness is likewise related to deficits in mental wellness, such as depression [21] and alexithymia [22]. Lonely adults also report greater dissatisfaction with their personal relationships [23].

Much scholarly speculation has addressed the question of why loneliness covaries with such detriments. One compelling explanation is found in Cacioppo's evolutionary theory of loneliness, which is detailed subsequently.

\subsection{Cacioppo's Evolutionary Theory of Loneliness}

Cacioppo's evolutionary theory explains loneliness as an evolved adaptation that promotes survival and reproduction $[9,10]$. Other things being equal, natural selection favors those individuals with characteristics that foster their survival to sexual maturity, because such individuals are better able to reproduce and contribute their genes to future generations [24]. Cacioppo and colleagues claimed that one such characteristic is an aversion to social exclusion. A predisposed drive for inclusion facilitates survival and reproduction because those who are motivated to connect with others gain benefits related to group inclusion, such as protection, shared resources, and reproductive opportunity [10]. In contrast, those who lack the motivation to bond with others may be less likely to survive hardships and more likely to have limited access to reproductive partners.

Because the drive for social inclusion is so strong, experiencing discomfort and distress during episodes of perceived social isolation therefore became adaptive within the human species, insofar as such feelings motivate a return to the group. As such, Cacioppo and colleagues argued, predispositions to experience anxiety in response to social isolation - a condition we know as loneliness-were selected for, increasing their odds of representation in future generations.

Social inclusion is adaptive, so loneliness - as a marker that this fundamental need is unmet-leads people to experience stress. Specifically, Cacioppo's theory suggests that feeling lonely increases one's feelings of vulnerability, anxiety, and surveillance of potential threats [25]. Unsurprising, then, loneliness often prompts a cognitive and physical threat response that triggers increased cortisol, inflammation, immunosuppression, and increases in blood glucose via the process of gluconeogenesis [26]. Consequently, loneliness is often associated with functional impairments such as daytime fatigue [27] and an inability to gain adequate restorative sleep [28].

In addition to coinciding with health deficits, feelings of anxiety and vulnerability to potential threat-such as those that correspond to loneliness - are also empirically related to politically conservative values, as described next.

\subsection{Linking Loneliness to Conservatism}

As an ideological orientation, political conservatism fundamentally reflects a motivation to preserve the existing order, prioritize safety and certainty over risk, and be wary of change. Jost, Glaser, Kruglanski, and Sulloway's motivated social cognition model explains that a conservative political orientation serves as an ego-defensive function against uncertainty, anxiety, and threat [29]. According to this model, the appeal of conservatism is that it depicts reality as concrete, consistent, and predictable. If loneliness prompts feelings of anxiety and vulnerability, as Cacioppo's evolutionary theory indicates, and if such feelings are commonly associated with politically conservative ideologies, then one logical deduction is that being lonely should correspond with having politically conservative values.

Several studies offer results supportive of such a proposition. For instance, Oxley and colleagues reported that having a conservative political orientation was associated with measurably greater physical sensitivities to sudden noise and threatening images, compared to having a more liberal orientation, suggesting that conservatism prompts stronger surveillance and a more defensive reaction to threat, as Cacioppo's theory would predict [30]. Similarly, in two large samples (total $N=31,045$ ), Inbar, Pizarro, Iyer, and Haidt found a positive relationship between political conservatism and sensitivity to disgust, even with several demographic variables and personality traits held constant [31]. Nail, McGregor, Drinkwater, Steele, and Thompson even demonstrated that conditions of threat cause people who normally have liberal political orientations to think more conservatively [32].

Moreover, like loneliness itself, conservatism is inversely related to physical health and wellness. In a nationwide sample of over 1.5 million Americans, Rentfrow et al. found that conservative ideology is negatively related to subjective well-being (-.23) and also to health-promoting behaviors (-.46) [33].

If loneliness prompts feelings of anxiety and vulnerability, and if such feelings typically characterize a 
more conservative than liberal orientation to political issues, then it is theoretically and empirically reasonable to predict that loneliness covaries with conservative attitudes on political issues. Three such issues that are often discussed as reflections of conservative thought are xenophobia, right-wing authoritarianism, and tolerance for distress.

Xenophobia. Xenophobia is defined as a "psychological state of hostility or fear towards outsiders" that often manifests in contempt of, and prejudice toward, immigrants and those perceived as foreign [34,35]. From the vantage point of evolutionary psychology, xenophobia reflects a fundamental bias of in-group over out-group members [36], one that appears to emerge early in development [37] and disposes people to judge out-group members more harshly with respect to characteristics such as competence and warmth [38]. Researchers have known for some time that xenophobia is positively associated with political conservatism, perhaps reflecting a conservative's preference for the safety of familiarity during feelings of vulnerability and threat [39]. Based on Cacioppo's proposition that loneliness induces similar emotional states, it is hypothesized that loneliness is positively associated with xenophobia (H1).

Right-wing authoritarianism. Altemeyer conceptualized right-wing authoritarianism (RWA) as a political value combining social conventionalism, submissiveness to authority, and authoritarian aggression [40]. RWA is sometimes distinguished conceptually from a related construct, social dominance orientation, with the former focusing on submission to in-group authority figures and the latter focusing on dominance over out-group members $[41,42]$. Several studies show RWA to be a precursor to prejudice against racial [43] and sexual [44] minorities, as well as greater emphasis on obedience and punishment in child-rearing practices [45]. Unsurprisingly, RWA is related to conservative political ideology, perhaps because it emphasizes the utility of conventionalism and order as responses to vulnerability [46]. Based on Cacioppo's theory that loneliness induces feelings of vulnerability and perceived threat, it is hypothesized that loneliness is positively associated with endorsement of right-wing authoritarianism $(\mathrm{H} 2)$.

Tolerance for distress. Distress tolerance indexes "the perceived or actual ability to withstand negative affect or other aversive psychological and/or physical states" [47]. Distress tolerance is inversely related to anxiety and the tendency to worry [48], as well as to subclinical post-traumatic stress [49]. Research shows that low tolerance for distress is associated with a range of maladaptive coping behaviors, including disordered eating [50], alcohol and cannabis abuse [51], tobacco dependence [52], and even a tendency to drop out prematurely from substance abuse treatment [53]. No investigations appear to have established a direct link between distress tolerance and political conservativism, but two studies have demonstrated that conservatively oriented individuals have exaggerated sensitivity to threat and disgust, compared to their more liberally oriented counterparts [30,31]. Similarly, Weise and colleagues showed that, under conditions of mortality threat, conservative political candidates were preferred over liberal candidates by those with insecure attachments, perhaps reflecting their generalized sense of vulnerability [54]. Based on Cacioppo's proposition that loneliness contributes to a similar sense of vulnerability, it is hypothesized that loneliness is negatively associated with tolerance for distress (H3).

Xenophobia, RWA, and distress tolerance are not the only constructs that index conservative political thought, but they are chosen for this initial investigation into the link between loneliness and conservatism because of their associations with conservative ideology. In addition to covarying with positions on political issues, it is also possible that loneliness corresponds to actual voting behavior for political candidates. It may be the case that loneliness is associated with a tendency to vote for conservative candidates [54], but it is similarly possible that loneliness corresponds to a tendency to abstain from voting altogether, as a means of protecting the self against perceived threats associated with social engagement, given that loneliness is also associated with withdrawal [55]. The link between loneliness and voting behavior was therefore examined in the form of a research question asking how loneliness is related to voting behavior in the previous U.S. presidential election (RQ1).

\section{Materials and Methods}

\subsection{Participants}

Participants $(N=848)$ were 419 men, 425 women, and 4 adults declining to indicate their biological sex, who ranged in age from 18 to 74 years, with an average age of 37.96 years $(S D=11.30)$. The participants came from 47 of 50 U.S. states and the District of Columbia. Most $(80.8 \%)$ self-identified as Caucasian, whereas $8.3 \%$ were Asian/Pacific Islander, 7.2\% were Black/African American, $5.3 \%$ were Hispanic or Latino/a, $1.5 \%$ were Native American, and $0.4 \%$ were of other ethnic origins (these percentages sum to $>100$ because some participants selected more than one ethnic identity). At the time of the study, $11.1 \%$ had completed a high school education or less, $16.8 \%$ had completed some higher education but had no degree, $23.9 \%$ had completed a vocational or trade school certificate or an associate's degree, $38.5 \%$ had completed a bachelor's degree, 8.0\% had completed a master's degree, and $1.7 \%$ had completed a doctoral degree. A power analysis ( $\mathrm{G}^{*}$ Power, Düsseldorf, Germany) indicated that the sample size provides $>99 \%$ power to detect medium effects and $>89 \%$ power to detect small effects at a .05 alpha error rate.

\subsection{Procedure and Measures}

Participants were recruited via the Amazon.com crowd sourcing marketplace Mechanical Turk (MTurk). To be eligible for the study, participants had to be at least 18 years old, be located in the United States, be able to read and write English, and be "master workers" (a designation indicating consistently high quality in submitted work) who had completed at least 100 previous jobs with an average approval rate equaling or exceeding 95\%. Eligible participants completed and submitted an online questionnaire in exchange for $\$ 1.25 \mathrm{US}$. Recent research has found that samples recruited on MTurk for academic research are typically more representative of the U.S. population than are in-person convenience samples [56,57]. 
Data were collected between January and May of 2016. During much of this period, candidates for the democratic and republican nominations for U.S. president were competing in U.S. state primary elections and caucuses. By the time data collection was finished, Hillary Clinton and Donald Trump were regularly referred to in mainstream media as their respective parties' presumptive nominees, but neither party had yet conducted its national convention.

Loneliness was assessed using the 20-item UCLA Loneliness Scale, version 3 [58], which includes 11 negatively worded items (e.g., "No one really knows me well") and 9 positively worded (reverse-scored) items (e.g., "There are people I feel close to"). Participants responded to the items using a 9-point scale, with higher scores indicating greater levels of loneliness. Coefficient alpha for this and all measures appears in Table 1.

Table 1. Means, Standard Deviations, Reliability Coefficients, and Intercorrelations for Study Variables $(\mathbf{N}=\mathbf{8 4 8})$

\begin{tabular}{lcccccc}
\hline Variable & $M$ & $S D$ & $\alpha$ & 1 & 2 & 3 \\
\hline 1. Loneliness & 3.66 & 1.89 & .97 & -- & & \\
2. Xenophobia & 3.52 & 2.10 & .95 & $.09 * *$ & -- & \\
3. Right-wing authoritarianism & 3.50 & 1.78 & .94 & -.02 & $.64^{* *}$ & -- \\
4. Distress tolerance & 3.51 & 1.79 & .95 & $.58^{* *}$ & $.15^{* *}$ & .06 \\
\hline
\end{tabular}

Notes. All variables were measured on 9-point scales. Higher scores indicate more loneliness, xenophobia, and authoritarianism, but less tolerance for distress. ${ }^{*} p<.05 ; * * p<.01$ (2-tailed).

Xenophobia was assessed using the 9-item xenophobia scale created by van der Veer et al. [59]. Using a 9-point scale, participants indicated their level of agreement with statements such as "Interacting with immigrants makes me uneasy" and "With increased immigration I fear that our way of life will change for the worse." Higher scores indicated greater levels of xenophobia.

Right-wing authoritarianism was measured with Zakrisson's short form of Altemeyer's Right-Wing Authoritarianism (RWA) scale [60]. This 15-item scale asks participants to indicate their level of agreement with statements such as "Our country needs a powerful leader, in order to destroy the radical and immoral currents prevailing in society today" and "Three are many radical, immoral people trying to ruin things; society ought to stop them." Responses employed a 9-point scale in which higher scores indicated stronger endorsement of right-wing authoritarianism.

Distress tolerance was assessed with Simons and Gaher's Distress Tolerance Scale (DTS) [61]. The DTS is a 14-item measure in which participants indicate their level of agreement with statements such as "I can't handle feeling distressed or upset" and "Feeling distressed or upset is unbearable to me." Participants responded to the items using a 9-point scale in which higher scores indicated less tolerance for distress, rather than more.

The order of items for all measures was randomized separately for each participant.

\section{Results}

Prior to testing the hypotheses and research question, the integrity of the data was carefully examined. Every MTurk worker has a unique respondent ID number, so to ensure that no worker performed the hit more than once, the frequencies for respondent ID number were examined and no numbers were duplicated, indicating that each respondent was unique. Time to completion (which averaged 14 minutes, 3 seconds) was also examined, and one questionnaire whose time to completion was more than two standard deviations below the mean was eliminated. In addition, responses to an attention check embedded in the questionnaire were examined, and ten participants were deleted for failing the attention check, resulting in the current sample size of 848 .

\subsection{Descriptive Statistics}

Participants' mean score for loneliness was $3.66(S D=1.89)$, indicating relatively mild loneliness, on average. Loneliness was mildly correlated with age, $r(845)=-.07, p$ (2-tailed) $=.035$, and did not vary as a function of sex, education level, or ethnicity. Means, standard deviations, and intercorrelations for all continuous variables appear in Table 1.

\subsection{Hypotheses and Research Question}

The first hypothesis predicted a positive association between loneliness and xenophobia. Xenophobia scores were significantly correlated with participants' age, $r(845)=.14, p(2$-tailed $)<.001$, but did not differ by sex, education level, or ethnicity. To control for the effect of age, the hypothesis was tested in a hierarchical multiple regression analysis, with xenophobia as the criterion variable. Age was entered in the first block of the regression as a control variable, and loneliness was entered in the second block. Cacioppo et al. suggested that loneliness may also evidence quadratic relationships with predicted outcomes when loneliness scores are positively skewed, as they were in this sample (skewness $=.67$, std. error $=.08)$, so a quadratic term for loneliness was initially entered in a third block [10]. The quadratic term proved nonsignificant, however, so it was removed in the service of parsimony. Consistent with H1, loneliness evidenced a significant linear relationship with xenophobia, $\beta=.11, p=.002$. Complete regression results appear in Table 2. The first hypothesis is supported.

\begin{tabular}{lcccc}
$\begin{array}{l}\text { Table 2. Multiple } \\
\text { Loneliness }(\mathbf{N}=\mathbf{8 4 8})\end{array}$ & Regression & Predicting & Xenophobia & from \\
\hline Models and Variables & $\mathrm{B}$ & $S E \mathrm{~B}$ & $\beta$ & $\Delta R^{2}$ \\
\hline 1. Age & 0.03 & 0.01 & $0.14^{* *}$ & -- \\
2. Age & 0.03 & 0.01 & $0.14^{* *}$ & $0.01^{*}$ \\
$\quad$ Loneliness & 0.12 & 0.04 & $0.11^{*}$ & \\
\hline
\end{tabular}

Notes. Zero-order correlations appear in Table 2. ${ }^{*} p<.05 ; * * p<.01 . R^{2}$ $=.03$, adjusted $R^{2}=.03, F(2,844)=12.32, p<.001$.

The second hypothesis called for a positive association between loneliness and endorsement of right-wing authoritarianism. RWA scores were significantly correlated with participants' age, $r(845)=.18, p(2$-tailed $)<.001$, but did not differ by sex, education level, or ethnicity. To control for the effect of age, the hypothesis was tested in a hierarchical multiple regression analysis, with RWA as the criterion variable. Age was entered in the first block, loneliness was entered in the second block, and a 
quadratic term for loneliness was entered in the third block. Consistent with $\mathrm{H} 2$, loneliness evidenced a significant linear relationship with RWA, $\beta=.28, p=.048$. Complete regression results appear in Table 3 . The quadratic term was also significant, $\beta=-.29, p=.038$. To interpret the quadratic effect, loneliness scores were divided into equally sized quintiles and means for RWA were calculated for each quintile. The means, which appear in Figure 1, indicate slightly higher RWA in the second-highest and second-lowest loneliness groups than in the remaining groups. The significant linear effect supports $\mathrm{H} 2$, but support is qualified by the quadratic effect.
Table 3. Multiple Regression Predicting Right-Wing Authoritarianism from Loneliness $(\mathrm{N}=\mathbf{8 4 8})$

\begin{tabular}{lcccc}
\hline Models and Variables & $\mathrm{B}$ & $S E \mathrm{~B}$ & $\beta$ & $\Delta R^{2}$ \\
\hline 1. Age & 0.03 & 0.01 & $.18^{* *}$ & -- \\
2. Age & 0.03 & 0.01 & $.18^{* *}$ & 0.00 \\
$\quad$ Loneliness & -0.01 & 0.03 & -.01 & \\
3. Age & 0.03 & 0.01 & $.19^{* *}$ & $0.01^{*}$ \\
$\quad$ Loneliness & 0.26 & 0.13 & $.28^{*}$ & \\
$\quad$ Loneliness (quadratic) & -0.03 & 0.02 & $-.29^{*}$ & \\
\hline
\end{tabular}

Notes. Zero-order correlations appear in Table $2 .{ }^{*} p<.05 ;{ }^{*} p<.01 . R^{2}$ $=.04$, adjusted $R^{2}=.03, F(3,843)=10.66, p<.001$.

\section{Right-Wing Authoritarianism}

3.8

3.7

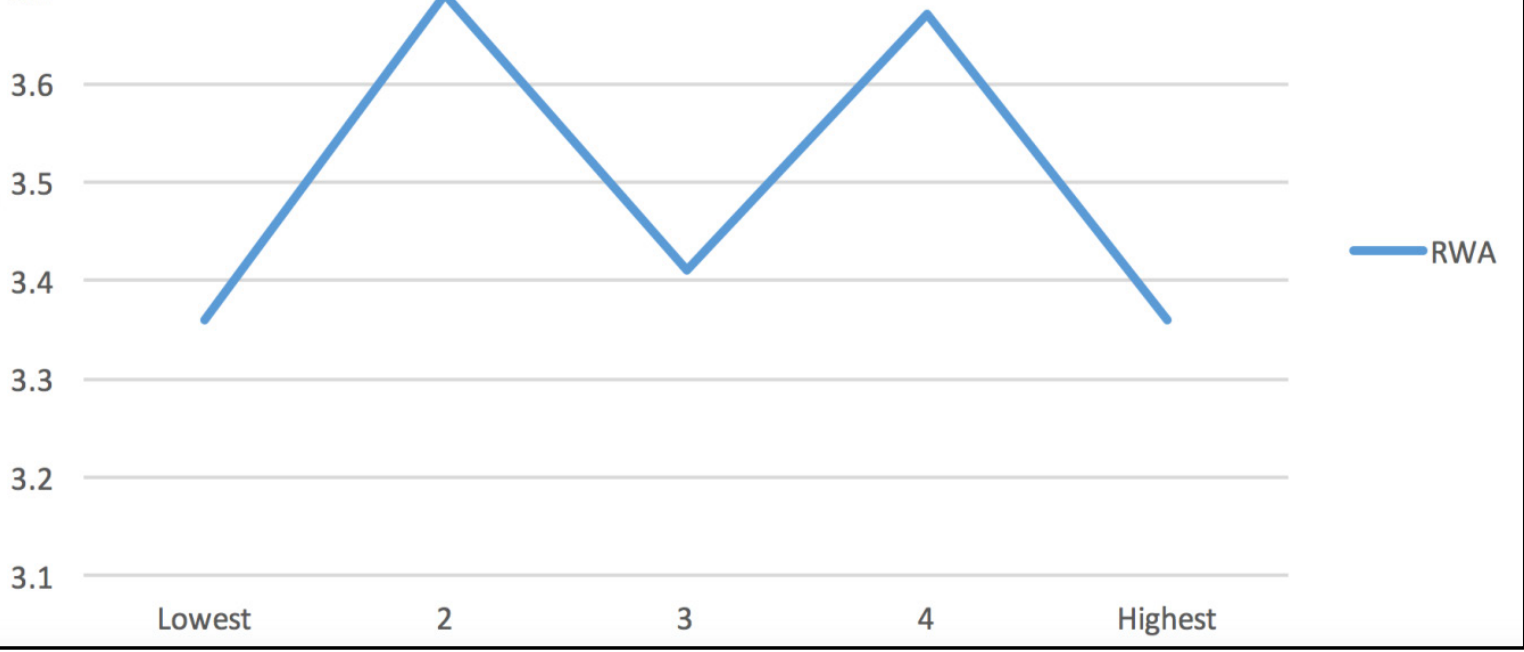

Figure 1. Scores for Endorsement of Right-Wing Authoritarianism Among Quintile Groups for Loneliness

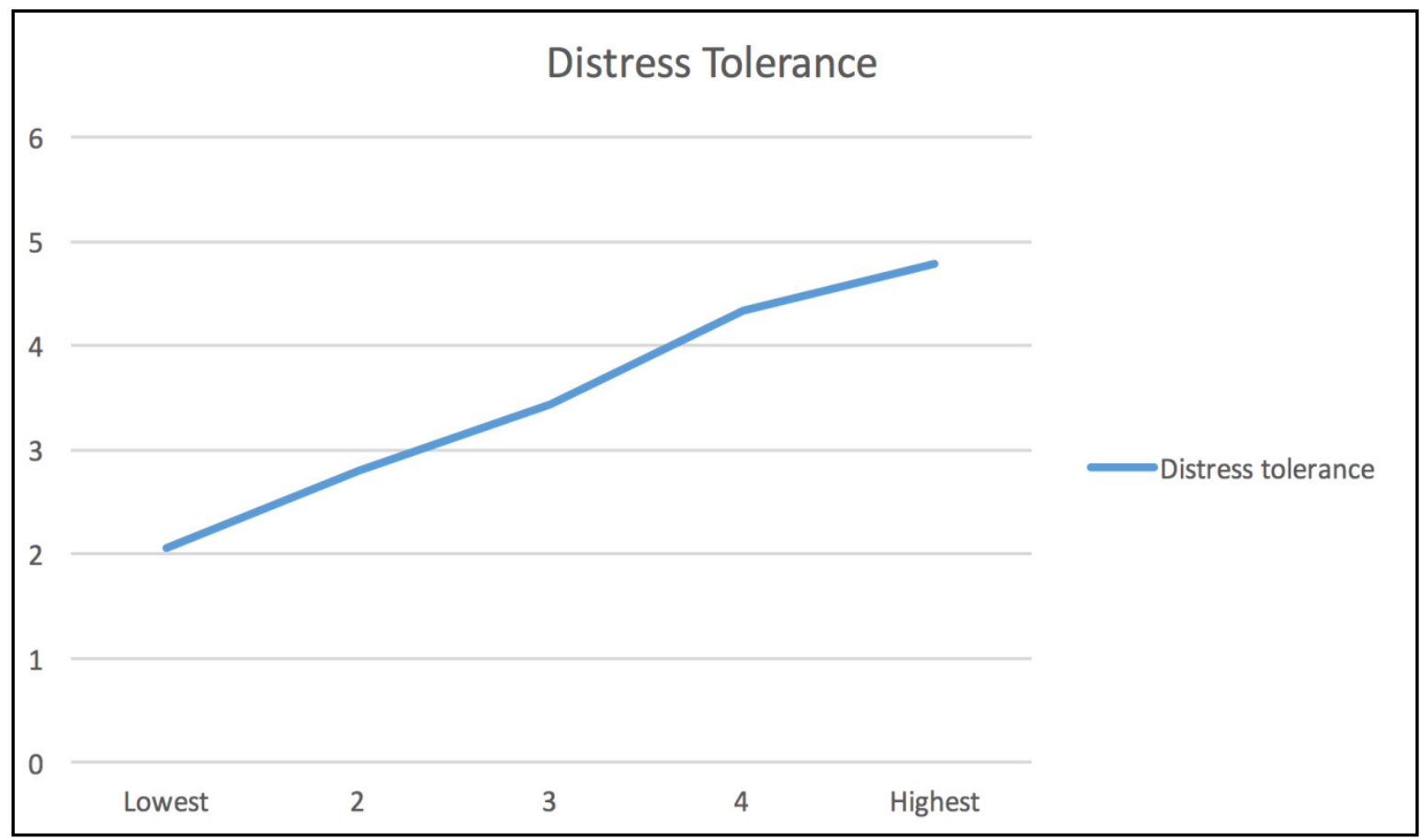

Figure 2. Scores for Distress Tolerance Among Quintile Groups for Loneliness 
Table 4. Multiple Regression Predicting Distress Tolerance from Loneliness $(\mathbf{N}=\mathbf{8 4 8})$

\begin{tabular}{lcccc}
\hline Models and Variables & $\mathrm{B}$ & $S E \mathrm{~B}$ & $\beta$ & $\Delta R^{2}$ \\
\hline 1. Age & -0.03 & 0.01 & $-.18^{* *}$ & -- \\
Sex & -0.43 & 0.13 & $-.12^{* *}$ & \\
2. Age & -0.02 & 0.01 & $-.14^{* *}$ & $0.32^{* *}$ \\
Sex & -0.43 & 0.10 & $-.12^{* *}$ & \\
Loneliness & 0.54 & 0.03 & $.57^{* *}$ & \\
3. Age & -0.02 & 0.01 & $-.13^{* *}$ & $0.01^{* *}$ \\
Sex & -0.44 & 0.10 & $-.12^{* *}$ & \\
Loneliness & 0.87 & 0.11 & $.91^{* *}$ & \\
Loneliness (quadratic) & -0.04 & 0.01 & $-.35^{* *}$ & \\
\hline
\end{tabular}

Notes. Zero-order correlations appear in Table 2. ${ }^{*} p<<.01 . R^{2}=.37$, adjusted $R^{2}=.36, F(4,839)=121.50, p<.001$.

The third hypothesis proposed that loneliness is negatively associated with tolerance for distress. In the operational definition of distress tolerance, higher scores index less tolerance for distress, so $\mathrm{H} 3$ actually calls for a positive statistical relationship between loneliness and distress tolerance, rather than an inverse relationship. Distress tolerance scores were significantly correlated with participants' age, $r(845)=-.16, p(2$-tailed $)<.001$, and were higher for women $(M=3.65, S D=1.92)$ than for men $(M=3.37, S D=1.66), t(842)=2.24, p(2$-tailed $)$ $=.025$, but did not differ by education level or ethnicity. To control for the effects of age and sex, the hypothesis was tested in a hierarchical multiple regression analysis, with distress tolerance as the criterion variable. Age and sex (dummy coded as $0=$ female, $1=$ male) were entered in the first block, loneliness was entered in the second block, and a quadratic term for loneliness was entered in the third block. Consistent with H3, loneliness evidenced a significant linear relationship with distress tolerance, $\beta=.91, p<.001$. Complete regression results appear in Table 4 . The quadratic term was also significant, $\beta=-.35$, $p=.002$. To interpret the quadratic effect, loneliness scores were divided into equally sized quintiles and means for distress tolerance were calculated for each quintile. The means, which appear in Figure 2, reflect the hypothesized linear relationship, with slight changes in the magnitude of the relationship. The significant linear effect and the shape of the significant quadratic effect both support H3.

The research question asked how loneliness is related to voting behavior in the immediate past U.S. presidential election, which at the time these data were collected was the 2012 election between republican Mitt Romney and democrat Barack Obama. For the research question, analysis was limited to participants 22 years of age or higher, as younger participants would not have been eligible to vote in the 2012 election. A oneway ANOVA was conducted, with voting behavior (voted for Mitt Romney, voted for Barack Obama, voted for someone else, did not vote) as the independent factor and loneliness as the dependent factor. The ANOVA produced a significant effect, $F(3,833)=5.40, p=.001, \eta^{2}=.02$, which was probed with the moderately conservative Student-Newman-Keuls post hoc test. Results indicated the highest loneliness score $(M=4.09, S D=1.97)$ among participants who did not vote. Those who did not vote were significantly lonelier than those who voted for Mitt Romney $(M=3.33, S D=2.01)$; all other mean comparisons were nonsignificant.

\section{Discussion}

Given the evolutionary importance of close relationships in the human social agenda, it is understandable that Cacioppo and colleagues would theorize that perceived social isolation-i.e., loneliness - is associated with anxiety, feelings of vulnerability, and perceptions of heightened threat. Indeed, such a proposition accounts for many extant findings connecting loneliness to elevated stress load, exaggerated stress responses, and functional deficits such as impaired sleep quality. Empirically, however, feelings of anxiety and vulnerability also coincide with politically conservative thought, so the current study investigated the logical deduction that loneliness corresponds with political conservatism.

That prediction was tested using three separate political characteristics - xenophobia, endorsement of right-wing authoritarianism, and tolerance for distress - on which politically conservative and politically liberal individuals tend to differ systematically. For each characteristic, loneliness was significantly associated with the more conservative position. Specifically, lonelier individuals reported higher xenophobia, stronger endorsement of right-wing authoritarianism, and lower distress tolerance. Effect sizes were moderate for xenophobia (.11) and RWA (.28) but substantial for distress tolerance (.91), indicating associations that are not inconsequential in their magnitude.

Of course, xenophobia, RWA, and distress tolerance are not the only potential political values that might be adjudicated. One might look at closely related constructs, such as ethnocentrism or social dominance orientation, and/or at positions on politically contentious social issues, such as gun control, gay marriage, or immigration. Indeed, no one construct - or probably even constellation of constructs-would fully operationalize one's political ideology. As a result, the present findings must be considered preliminary and subject to further investigation with other political outcomes. It may even be the case that loneliness is more strongly associated with some dimensions of conservative thought (such as social conservatism) than with others (such as fiscal conservatism), insofar as feelings of anxiety and vulnerability may affect social and fiscal ideologies differently. Such possibilities await investigation in future studies.

Some may wonder why the hypothesized connection between loneliness and conservatism was not investigated simply by comparing the loneliness scores of registered democrats and registered republicans. The current approach - of examining scores on politically charged issues - is superior for at least two reasons. First, the logically derived prediction was that loneliness covaried with politically conservative thought, not with party identification, and although party identification may be a reliable surrogate for political ideology, the focus was on how participants believe rather than on which label they identify with. Second, there is likely substantial within- 
group variance among both registered republicans and registered democrats in political ideology, which would be treated as error by merely comparing one cell to the other. Examining continuous scores on political values also preserves systematic variance that would be lost in simply comparing two political parties.

The present study also demonstrated that loneliness is associated with previous voting behavior - at least in the immediate past U.S. presidential election. Rather than corresponding with a tendency to vote for the republican candidate, however, loneliness was associated with not voting at all. Behaviorally, loneliness often predicts social avoidance and withdrawal more than social approach-even though withdrawal perpetuates, rather than remedies, the deficit in social connection - so loneliness may well have prompted participants to avoid the social engagement involved in voting [62]. Of course, voting by mail-in ballot might assuage that concern, and it is possible that loneliness is associated with voting by mail as well as with failing to vote altogether. The present study asked only about whether and for whom participants voted, however, rather than how they voted, so investigating such a possibility would require further research.

\section{Conclusion}

Considered in concert, the present findings lend additional credence to Cacioppo and colleagues' theory that the evolutionary adaptiveness of social inclusion and connection makes loneliness anxiety-producing and aversive. A logical derivation from that thesis is that loneliness is associated with conservatism, so support for that hypothesis implies support for the theory. The findings also add to empirical understanding of loneliness by broadening the range of life domains known to correspond to that condition. Whereas previous studies have articulated how loneliness covaries with mental wellness, physical health, and relational well-being, this is perhaps the first study to connect loneliness with one's orientation to, and engagement in, political life.

Until these initial findings are replicated and extended, it may be premature to suggest practical implications. One potential implication, however, is that supporters of politically conservative initiatives may find support by appealing to constituencies known to score high in loneliness. In the United States, data suggest that those constituencies would include the elderly and voting-age adolescents and may also include the infirm, the recently relocated, those living in rural or isolated locales, those who are divorced or widowed, and those living apart from their spouses or partners due to employment, incarceration, or military deployment. Appealing to individuals in such constituencies - and perhaps also facilitating their involvement in voting by mail-in ballot-may result in greater support for conservative political issues or candidates. A corresponding implication is that interpersonal efforts directed at establishing or renewing social connection with lonely individuals, to the extent that such efforts reduce loneliness, may effect changes in political sensibilities, such as encouraging less-conservative thought. These implications are speculative, however, and require further investigation.
The present study benefited by a demographically and geographically diverse sample of adults representing nearly every U.S. state. The sample was restricted to those who could read and write English, had internet connectivity, and were master MTurk workers, so it certainly was not fully representative of the U.S. adult population but did evidence more diversity than is often observed in loneliness research. As noted above, the current study is also limited by its inclusion of only three political value measures (xenophobia, RWA, and distress tolerance); future research will benefit by including a broader range of measures.

\section{Acknowledgements}

None.

\section{Statement of Competing Interests}

The author has no competing interests.

\section{References}

[1] Maslow, A. H. "A theory of human motivation," Psychological Review, 50(4), 370-396. 1943

[2] Schutz, W. C. FIRO: A three-dimensional theory of interpersonal behavior. Holt, Rinehart \& Winston, New York, 1958.

[3] Baumeister, R. F., and Leary, M. R. "The need to belong: Desire for interpersonal attachments as fundamental human motivation," Psychological Bulletin, 117(3), 497-529. May 1995.

[4] Cacioppo, J. T., and Patrick, W. Loneliness: Human nature and the need for social connection. W. W. Norton, New York, 2008.

[5] Floyd, K. "Relational and health correlates of affection deprivation," Western Journal of Communication, 78(4), 383-403. September 2014.

[6] House, J. "Social isolation kills, but how and why?" Psychosomatic Medicine, 63(2), 273-274. March/April 2001.

[7] Cacioppo, J. T., and Cacioppo, S. "Social relationships and health: The toxic effects of perceived social isolation," Social and Personality Psychology Compass, 8(2), 58-72. February 2014.

[8] Steptoe, A., Shankar, A., Demakakos, P., and Wardle, J. "Social isolation, loneliness, and all-cause mortality in older men and women," Proceedings of the National Academy of Sciences, 110(15), 5797-5801. April 2013.

[9] Cacioppo, J. T., Cacioppo, S., and Boomsma, D. "Evolutionary mechanisms for loneliness," Cognition and Emotion, 28(1), 3-21. 2013.

[10] Cacioppo, J. T., Hawkley, L. C., Ernst, J. M., Burleson, M., Berntson, G. G., Nouriani, B., and Spiegel, D. "Loneliness within a nomological net: An evolutionary perspective," Journal of Research in Personality, 40(6), 1054-1085. December 2006.

[11] Victor, C. R., and Yang, K. "The prevalence of loneliness among adults: A case study of the United Kingdom," Journal of Psychology, 146(1-2), 85-104. January/April 2012.

[12] American Association of Retired Persons. Loneliness among older adults: A national survey of adults 45+. AARP, Washington, DC, 2010.

[13] Theeke, L. A. "Predictors of loneliness in U.S. adults over age sixty-five," Archives of Psychiatric Nursing, 23(5), 387-396. October 2009

[14] Golden, J., Conroy, R. M., Bruce, I., Denihan, A., Greene, E., Kirby, M., and Lawlor, B. A. "Loneliness, social support networks, mood and wellbeing in community-dwelling elderly," International Journal of Geriatric Psychiatry, 24(7), 694-700. July 2009.

[15] Simon, M. A., Chang, E.-S., Zhang, M., Ruan, J., and Dong, X. "The prevalence of loneliness among U.S. Chinese older adults," Journal of Aging and Health, 26(7), 1172-1188. October 2014. 
[16] Jaremka, L. M., Fagundes, C. P., Glaser, R., Bennett, J. M., Malarkey, W. B., and Kiecolt-Glaser, J. K. "Loneliness predicts pain, depression, and fatigue: Understanding the role of immune dysregulation," Psychoneuroendocrinology, 38(8), 1310-1317. August 2013.

[17] Kurina, L. M., Knutson, K. L., Hawkley, L. C., Cacioppo, J. T., Lauderdale, D. S., and Ober, C. "Loneliness is associated with sleep fragmentation in a communal society," Sleep, 34(11), 15191526. November 2011.

[18] Momtaz, Y. A., Hamid, T. A., Yusoff, S., Ibrahim, R., Chai, S. T., Yahaya, N., and Abdullah, S. S. "Loneliness as a risk factor for hypertension in later life," Journal of Aging and Health, 24(4), 696-710. June 2012.

[19] Shankar, A., McMunn, A., Banks, J., and Steptoe, A. "Loneliness, social isolation, and behavioral and biological health indicators in older adults," Health Psychology, 30(4), 377-385. July 2011.

[20] Jaremka, L. M., Fagundes, C. P., Peng, J., Bennett, J. M., Glaser, R., Malarkey, W. B., and Kiecolt-Glaser, J. K. "Loneliness promotes inflammation during acute stress," Psychological Science, 24(7), 1089-1097. July 2013.

[21] Aylaz, R., Aktürk, Ü., Erci, B., Öztürk, H., and Aslan, H. "Relationship between depression and loneliness in elderly and examination of influential factors," Archives of Gerontology and Geriatrics, 55(3), 548-554. November/December 2012.

[22] Qualter, P., Quinton, S. J., Wagner, H., and Brown, S. "Loneliness, interpersonal distrust, and alexithymia in university students," Journal of Applied Social Psychology, 39(6), 1461-1479. June 2009.

[23] Frye-Cox, N. E., and Hesse, C. "Alexithymia and marital quality: The mediating roles of loneliness and intimate connection," Journal of Family Psychology, 27(2), 203-211. April 2013.

[24] Dawkins, R. The selfish gene. Oxford University Press, New York, 1990.

[25] Bangee, M., Harris, R. A., Bridger, N., Rotenberg, J. J., and Qualter, P. "Loneliness and attention to social threat in young adults: Findings from an eye tracker study," Personality and Individual Differences, 63, 16-23. June 2014.

[26] Cacioppo, J. T., Cacioppo, S., Capitanio, J. P., and Cole, S. W. "The neuroendocrinology of social isolation," Annual Review of Psychology, 66, 733-767. January 2015.

[27] Hawkley, L. C., Preacher, K. J., and Cacioppo, J. T. "Loneliness impairs daytime functioning but not sleep duration," Health Psychology, 29(2), 124-129. March 2010.

[28] Cacioppo, J. T., Hawkley, L. C., Berntson, G. G., Ernst, J. M., Gibbs, A. C., Stickgold, R., and Hobson, J. A. "Do lonely days invade the nights? Potential social modulation of sleep efficiency," Psychological Science, 13(4), 384-387. July 2002.

[29] Jost, J. T., Glaser, J., Kruglanski, A. W., and Sulloway, F. J. "Political conservatism as motivated social cognition," Psychological Bulletin, 129(3), 339-375. 2003.

[30] Oxley, D. R., Smith, K. B., Alford, J. R., Hibbing, M. V., Miller, J., Scalora, M., Hatemi, P. K., and Hibbing, J. R. "Political attitudes vary with physiological traits," Science, 321(5896), 1667-1670. September 2008.

[31] Inbar, Y., Pizarro, D., Iyer, R., and Haidt, J. "Disgust sensitivity, political conservatism, and voting," Social Psychological \& Personality Science, 3(5), 537-544. 2012.

[32] Nail, P. R., McGregor, I., Drinkwater, A. E., Steele, G. M., and Thompson, A. W. "Threat causes liberals to think like conservatives," Journal of Experimental Social Psychology, 45(4), 901-907. July 2009.

[33] Rentfrow, P. J., Gosling, S. D., Jokela, M., Stillwell, D. J., Kosiski, M., and Potter, J. "Divided we stand: Three psychological regions of the United States and their political, economic, social, and health correlates," Journal of Personality and Social Psychology, 105(6), 996-1012. December 2013.

[34] Reynolds, V., Falger, V., and Vine, I. (1987). The sociobiology of ethnocentrism: Evolutionary dimensions of xenophobia, discrimination, racism and nationalism. University of Georgia Press, Athens, 1987.

[35] Yakushko, O. "Xenophobia: Understanding the roots and consequences of negative attitudes toward immigrants," The Counseling Psychologist, 37(1), 36-66. 2009.

[36] Halevy, N., Weisel, O., and Bornstein, G. “'In-group love' and 'out-group hate' in repeated interaction between groups," Journal of Behavioral Decision Making, 25(2), 188-195. April 2012.
[37] Buttelmann, D., Zmyj, N., Daum, M., and Carpenter, M. "Selective imitation of in-group over out-group members in 14month-old infants," Child Development, 84(2), 422-428. March/April 2013.

[38] Fiske, S. T., Cuddy, A. J. C., Glick, P., and Xu, J. "A model of (often mixed) stereotype content: Competence and warmth respectively follow from perceived status and competition," Journal of Personality and Social Psychology, 82(6), 878-902. June 2002.

[39] Stewart, R. A. C., and Webster, A. C. "Scale for theological conservatism, and its personality correlates," Perceptual and Motor Skills, 30(3), 867-870. June 1970.

[40] Altemeyer, B. Right-wing authoritarianism. University of Manitoba Press, Winnipeg, 1981.

[41] Altemeyer, B. "The other 'authoritarian personality,"” Advances in Experimental Social Psychology, 30, 47-92. 1998.

[42] Sidanius, J., and Pratto, F. Social dominance. Cambridge University Press, Cambridge, 1999.

[43] Laythe, B., Finkel, D., and Kirkpatrick, L. A. "Predicting prejudice from religious fundamentalism and right-wing authoritarianism: A multiple-regression approach," Journal for the Scientific Study of Religion, 40(1), 1-10. March 2001.

[44] Hunsberger, B. "Religious fundamentalism, right-wing authoritarianism, and hostility toward homosexuals in nonChristian religious groups," The International Journal for the Psychology of Religion, 6(1), 39-49. 1996.

[45] Danso, H., Hunsberger, B., and Pratt, M. "The role of parental religious fundamentalism and right-wing authoritarianism in childrearing goals and practices," Journal for the Scientific Study of Religion, 36(4), 496-511. December 1997.

[46] Smith, A. G., and Winter, D. G. "Right-wing authoritarianism, party identification, and attitudes toward feminism in student evaluations of the Clinton-Lewinsky story," Political Psychology, 23(2), 355-383. June 2002.

[47] Leyro, T. M., Bernstein, A., Vujanovic, A. A., McLeish, A. C., and Zvolensky, M. J. "Distress tolerance scale: A confirmatory factor analysis among daily cigarette smokers," Journal of Psychopathology and Behavioral Assessment, 33(1), 47-57. March 2011.

[48] Keough, M. E., Riccardi, C. J., Timpano, K. R., Mitchell, M. A., and Schmidt, N. B. "Anxiety symptomatology: The association with distress tolerance and anxiety sensitivity," Behavior Therapy, 41(4), 567-574. December 2010.

[49] Vujanovic, A. A., Bonn-Miller, M. O., Potter, C. M., Marshall, E. C., and Zvolensky, M. J. "An evaluation of the relation between distress tolerance and posttraumatic stress within a traumaexposed sample," Journal of Psychopathology and Behavioral Assessment, 33(1), 129-135. March 2011.

[50] Corstorphine, E., Mountford, V., Tomlinson, S., Waller, G., and Meyer, C. "Distress tolerance in the eating disorders," Eating Behaviors, 8(1), 91-97. January 2007.

[51] Buckner, J. D., Keough, M. E., and Schmidt, N. B. "Problematic alcohol and cannabis use among young adults: The roles of depression and discomfort and distress tolerance," Addictive Behaviors, 32(9), 1957-1963. September 2007.

[52] Brown, R. A., Lejuez, C. W., Kahler, C. W., Strong, D. R., and Zvolensky, M. J. "Distress tolerance and early smoking lapse," Clinical Psychology Review, 25(6), 713-733. September 2005.

[53] Daughters, S. B., Lejuez, C. W., Bornovalova, M. A., Kahler, C. W., Strong, D. R., and Brown, R. A. "Distress tolerance as a predictor of early treatment dropout in a residential substance abuse treatment facility," Journal of Abnormal Psychology, 114(4), 729-734. November 2005.

[54] Weise, D. R., Pyszczynski, T., Cox, C. R., Arndt, J., Greenberg, J., Solomon, S., and Kosloff, S. "Interpersonal politics: The role of terror management and attachment processes in shaping political preferences," Psychological Science, 19(5), 448-455. May 2008.

[55] Watson, J., and Nesdale, D. "Rejection sensitivity, social withdrawal, and loneliness in young adults," Journal of Applied Social Psychology, 42(8), 1984-2005. August 2012.

[56] Berinsky, A. J., Huber, G. A., and Lenz, G. S. "Evaluating online labor markets for experimental research: Amazon.com's Mechanical Turk," Political Analysis, 20(3), 351-368. May 2012.

[57] Paolacci, G., Chandler, J., and Ipeirotis, P. G. "Running experiments on Amazon Mechanical Turk," Judgment and Decision Making, 5(5), 411-419. July 2010. 
[58] Nurmi, J.-E., Toivonen, S., Salmela-Aro, K., and Eronen, S. "Optimistic, approach-oriented, and avoidance strategies in social situations: Three studies on loneliness and peer relationships," European Journal of Personality, 10(3), 201-219. September 1996.

[59] Zakrisson, I. "Construction of a short version of the Right-Wing Authoritarianism (RWA) scale," Personality and Individual Differences, 39(5), 863-872. October 2005.

[60] Russell, D. "UCLA loneliness scale (version 3): Reliability, validity, and factor structure," Journal of Personality Assessment, 66(1), 20-40. February 1996.
[61] Simons, J., and Gaher, R. "The Distress Tolerance Scale: Development and validation of a self-report measure," Motivation and Emotion, 29(2), 83-102. June 2005.

[62] van der Veer, K., Ommundsen, R., Yakusko, O., Higler, L., Woelders, S., and Hagen, K. A. "Psychometrically and qualitatively validating a cross-national cumulative measure of fear-based xenophobia," Quality \& Quantity: International Journal of Methodology, 47(3), 1429-1444. April 2013. 